\title{
Disappointing dipstick screening for urinary tract infection in hospital inpatients
}

\author{
Z Zaman, A Borremans, J Verhaegen, L Verbist, N Blanckaert
}

\begin{abstract}
Aim-To compare the performance of leucocyte esterase and nitrite dipstick tests with microscopic examination and culture of first morning urines $(n=420)$ of hospital inpatients.

Results-The sensitivity, specificity, and negative predictive value of the leucocyte esterase test for the cutoff of $>10 \mathrm{WBC} / \mu \mathrm{l}$ were $57 \%, 94 \%$, and $68 \%$, respectively. For $>5$ WBC per high power field (HPF) these variables were $84 \%, 90 \%$, and $93 \%$. For $>10^{5}$ colony counts $/ \mathrm{ml}$, the sensitivity of the nitrite test was $27 \%$, specificity $94 \%$, and negative predictive value $87 \%$. When either leucocyte esterase or nitrite positivity was accepted as a marker of urinary tract infection, the sensitivity was $78 \%$, specificity $75 \%$, and negative predictive value $94 \%$, and there were $22 \%$ false negative results. Semiquantitative microscopic estimation of bacteria per HPF yielded $40 \%$ false positives.

Conclusions-Leucocyte esterase and nitrite dipstick tests are not suitable for screening for urinary tract infections. (F Clin Pathol 1998;51:471-472)
\end{abstract}

Keywords: leucocyte esterase; nitrite; dipstick

Screening of urine specimens for urinary tract infection by means of dipstick leucocyte esterase and nitrite test is not an uncommon practice, although the standard method for diagnosis of infected urine remains microscopic examination and quantitative culture of urine. We have evaluated the diagnostic performance of the dipstick test in hospital inpatients in comparison with the microscopic and culture results.

Table 1 Performance of urine dipstick tests in comparison with microscopic and culture results

\begin{tabular}{|c|c|c|c|c|c|c|c|c|}
\hline Positive screening test & Reference cutoff & $n$ & $\% F N$ & $\% F P$ & $\% \operatorname{Sen}$ & $\%$ Spec & $\% P P V$ & $\% N P V$ \\
\hline \multirow{5}{*}{ Leucocyte esterase (LE) } & $>10 \mathrm{WBC} / \mu \mathrm{l}$ & 204 & $43(87)$ & $6(11)$ & 57 & 94 & 91 & 68 \\
\hline & $>20 \mathrm{WBC} / \mu \mathrm{l}$ & 136 & $23(32)$ & $9(24)$ & 77 & 91 & 81 & 88 \\
\hline & $>5 \mathrm{WBC} / \mathrm{HPF}$ & 126 & $16(20)$ & $11(31)$ & 84 & 90 & 77 & 93 \\
\hline & $\geqslant 5 \times 10^{4} \mathrm{CFU} / \mathrm{ml}$ & 90 & $31(28)$ & $23(75)$ & 69 & 77 & 45 & 90 \\
\hline & $\geqslant 10^{5} \mathrm{CFU} / \mathrm{ml}$ & 72 & $26(19)$ & $24(84)$ & 74 & 76 & 39 & 93 \\
\hline \multirow[t]{2}{*}{ Nitrite } & $\geqslant 5 \times 10^{4} \mathrm{CFU} / \mathrm{ml}$ & 90 & $73(66)$ & $7(22)$ & 27 & 93 & 51 & 82 \\
\hline & $\geqslant 10^{5} \mathrm{CFU} / \mathrm{ml}$ & 72 & $67(48)$ & $6(22)$ & 33 & 94 & 52 & 87 \\
\hline \multirow[t]{2}{*}{ Nitrite or LE } & $\geqslant 5 \times 10^{4} \mathrm{CFU} / \mathrm{ml}$ & 90 & $28(25)$ & $23(77)$ & 72 & 77 & 46 & 91 \\
\hline & $\geqslant 10^{5} \mathrm{CFU} / \mathrm{ml}$ & 72 & $22(16)$ & $25(86)$ & 78 & 75 & 39 & 94 \\
\hline \multirow[t]{2}{*}{ Nitrite plus LE } & $\geqslant 5 \times 10^{4} \mathrm{CFU} / \mathrm{ml}$ & 90 & 77 (69) & $6(20)$ & 23 & 94 & 51 & 82 \\
\hline & $\geqslant 10^{5} \mathrm{CFU} / \mathrm{ml}$ & 72 & $71(51)$ & $6(20)$ & 29 & 94 & 51 & 87 \\
\hline \multirow[t]{2}{*}{ Signif bacteria/HPF } & $\geqslant 5 \times 10^{4} \mathrm{CFU} / \mathrm{ml}$ & 90 & $17(15)$ & $40(131)$ & 83 & 60 & 36 & 93 \\
\hline & $\geqslant 10^{5} \mathrm{CFU} / \mathrm{ml}$ & 72 & $8(6)$ & $40(140)$ & 92 & 60 & 32 & 97 \\
\hline
\end{tabular}

CFU, colony forming units; FN, false negative; FP, false positive; HPF, high power field; NPV, negative predictive value; PPV, positive predictive value; Sen, sensitivity; Spec, specificity.

Figures in brackets represent numbers of cases.

\section{Methods}

Over a three week period, 420 first morning urine samples from hospital inpatients on which urine cultures had been requested were randomly selected for additional tests. These tests included (1) test strip screening with multistix 8 SG (Bayer Corporation, New York, USA), (2) direct microscopic counting of the white blood cells (WBC) and bacteria per microlitre of urine using Kova counting chambers (Hycor Biomedical Inc, California, USA), (3) urine sediment microscopy, after centrifugation at $350 \mathrm{~g}$ for five minutes, to obtain WBC and bacteria per high power field (HPF). The strips were read by reflectance spectrophotometric method on Clinitek 200+ (Bayer).

Urine cultures were performed by inoculating, from a standard loop, $10 \mu \mathrm{l}$ of uncentrifuged and well mixed urines on to blood agar and MacConkey plates (Oxoid, Hampshire, UK) and incubating aerobically at $37^{\circ} \mathrm{C}$ overnight. Growth of $\leqslant 10000$ colony forming units (CFU) per $\mathrm{ml}$ was considered negative.

The patients consisted of 234 females (mean age 55 years, range 17 days to 97 years) and 186 males (mean age 58 years, range 9 to 94 years) and they belonged to the following general groups: paediatrics (4), oncology (5), obstetrics/gynaecology (39), surgery (51), geriatrics (57), ambulant consultation (68), internal medicine (93) and medical and postoperative intensive care (103).

\section{Results}

Using the standard criterion of $\geqslant 10^{5} \mathrm{CFU} / \mathrm{ml}$ for urinary tract infection, 72 patients' urines (17\%) produced positive cultures. Of these 18 $(25 \%)$ were infected with non-nitrate-reducing organism, these being mainly enterococci and candida. With a less stringent criterion of
Z Zaman

N Blanckaert

Department of Information Systems A Borremans

Laboratory of

Bacteriology

J Verhaegen

L Verbist

Correspondence to: Dr Z Zaman, Central Clinical Laboratory, University Hospitals Leuven,

Herestraat 49, B-3000

Leuven, Belgium;

email: zahur.zaman

uz.kuleuven.ac.be

Accepted for publication 11 March 1998 
$\geqslant 5 \times 10^{4} \mathrm{CFU} / \mathrm{ml}, 90$ patients $(21 \%)$ could be considered positive for urinary tract infection. Two hundred and six specimens were positive for significant bacteria ( $>50$ bacteria/HPF) by microscopic examination of the sediment.

The diagnostic performance of the Multistix tests for leucocyte esterase and nitrite was assessed at different cutoff levels of WBC and CFU per ml of urine, respectively. The results are shown in table 1 .

\section{Discussion}

Multistix test for WBC measures leucocyte esterase of neutrophil granules and has analytical sensitivity of $10-25 \mathrm{WBC} / \mu 1$ or $5-15 \mathrm{WBC} /$ HPF (manufacturer's data sheet). The nitrite test is an indirect measure of nitrate reducing bacteria (which include all enterobacteria, and most non-fermenters and Gram negative cocci) provided urine contains sufficient dietary nitrate and has been retained in the bladder for longer than four hours. This test is sensitive to $\geqslant 13 \mu \mathrm{mol} / 1$ nitrite.

Of 420 specimens, 204 contained $>10$ $\mathrm{WBC} / \mu \mathrm{l}$ and $126 \mathrm{had}>5 \mathrm{WBC} / \mathrm{HPF}$. The diagnostic sensitivity, specificity, and positive predictive value of the leucocyte esterase test were $57 \%, 94 \%$, and $91 \%$, respectively, for $>10 \mathrm{WBC} / \mu \mathrm{l}$, and $84 \%, 90 \%$, and $77 \%$ for $>5$ $\mathrm{WBC} / \mathrm{HPF}$ (our reference intervals being $<10$ $\mathrm{WBC} / \mu \mathrm{l}$ and/or $<5 \mathrm{WBC} / \mathrm{HPF}$ ). False negative leucocyte esterase results at these cutoff levels of WBC were respectively $43 \%$ and $16 \%$. Raising the diagnostic cutoff for $\mathrm{WBC} / \mu \mathrm{l}$ to $>20$ $\mathrm{WBC} / \mu \mathrm{l}$ improves the sensitivity $(77 \%)$ and negative predictive value $(88 \%)$, but the false negative results still remained high at $23 \%$. This makes the leucocyte esterase test unsuitable surrogate of microscopic examination for WBC.

The reference intervals for urinary WBC of $<10 \mathrm{WBC} / \mu \mathrm{l}$ and $<5 \mathrm{WBC} / \mathrm{HPF}$ imply that these limits are equivalent. This assumption was not substantiated by our results. Whereas 204 urines had $>10 \mathrm{WBC} / \mu \mathrm{l}$, only 126 samples were found to contain $>5 \mathrm{WBC} / \mathrm{HPF}$. On the other hand the results for cutoff values of $>20$ $\mathrm{WBC} / \mu \mathrm{l}$ and $>5 \mathrm{WBC} / \mathrm{HPF}$ were similar. This clearly showed-albeit indirectly-that the common reference intervals of $<10 \mathrm{WBC} / \mu \mathrm{l}$ and $<5 \mathrm{WBC} / \mathrm{HPF}$ are not equivalent. There is no ready method for interconverting results per HPF and results per $\mu 1$. Nevertheless it can be stated that $>5 \mathrm{WBC} / \mathrm{HPF}$ is probably more nearly equivalent to $>20 \mathrm{WBC} / \mu \mathrm{l}$ than to $>10$ WBC $/ \mu 1$.

For the detection of bacteria, the diagnostic sensitivity of the nitrite test was $27 \%$ for $\geqslant 5 \times$ $10^{4} \mathrm{CFU} / \mathrm{ml}$ and $33 \%$ for $\geqslant 10^{5} \mathrm{CFU} / \mathrm{ml}$. When either a nitrite positive or a leucocyte esterase positive result was used for the diagnosis of urinary tract infection, the diagnostic sensitivity improved at the cost of specificity, while the opposite was true when both nitrite and leucocyte esterase were required to be positive for the detection of infected urine. Although the negative predictive value for the nitrite/leucocyte esterase positive combination was more than $90 \%$, the false negative rate of $>20 \%$ is unacceptably high for hospital inpatients (see table 1). This is also borne out by the fact that even when urine contained $\geqslant 10^{5}$ nitrite producing bacteria $/ \mathrm{ml}$, only $43 \%$ samples yielded positive results with the nitrite test. When we further subdivided the patients with $\geqslant 10^{5}$ nitrite producing bacteria/ml $(\mathrm{n}=72)$ into those from whom urine was collected from an indwelling catheter $(\mathrm{n}=23)$ and those who voided unaided $(\mathrm{n}=$ $49)$ we found that 19 patients $(83 \%)$ with indwelling catheters and $29(59 \%)$ of the self voiding patients had negative nitrite test results. The poor concordance between the culture and the nitrite test results in these inpatients may have been the result of short contact time, reduced nitrate excretion, or dilution of urine by large volumes of intravenous infusions.

Microscopic estimates of significant bacteria $(>50$ bacteria/HPF) in the urine sediments gave $40 \%$ false positive results. Although negative predictive values would indicate (see table 1) that the microscopic estimation of bacteria in the sediments is a good screening method, this needs to be weighed against false negative rates of $17 \%$ and $8 \%$ for the urines of hospital inpatients containing $\geqslant 5 \times 10^{4} \mathrm{CFU} / \mathrm{ml}$ and $\geqslant 10^{5} \mathrm{CFU} / \mathrm{ml}$, respectively.

From this study we conclude that because of their high false negative rates the leucocyte esterase and nitrite dipstick tests are not suitable for screening of hospital inpatients for urinary tract infections. This conclusion is supported in different settings by other published reports with respect to leucocyte esterase, ${ }^{1}$ nitrate ${ }^{2}$ and leucocyte esterase and nitrite tests. $^{3}$ Two groups, however, have reported that dipstick tests are a good screening method for urinary tract infections in new paediatric patients. ${ }^{45}$ With a false positive result rate of $40 \%$, semiquantitative microscopic estimation of bacteria (per HPF or per $\mu \mathrm{l})$ is also an unreliable marker of infected urine.

1 Patrick DM, Rekart ML, Knowles L. Unsatisfactory performances of the leukocyte esterase test of first voided urine for rapid diagnosis of urethritis. Genitourin Med 1994;70:187-90

2 Backman JW, Heise RH, Naessens JM, et al. A study of various tests to detect asymptomatic urinary tract infections in an obstetric population. $\mathscr{f} A M A$ 1993;270:1971-4.

3 Propp DA, Weber D, Ciesla ML. Reliability of a urine dipstick in emergency department patients. Ann Emerg Med 1989;18:560-3.

4 Molyneux EM, Robson WJ. A dipstick test of urinary tract infections. 7 Accid Emerg Med 1995;12:191-3.

5 Woodward MN, Griffiths DM. Use of dipsticks for routine analysis of urine from children with acute abdominal pain. BMF 1993;306:1512. 